\title{
LA SOLANA DEL CASTELL DE XÀTIVA DESDE LA PREHISTORIA HASTA LA LLEGADA DE ROMA
}

\author{
José Pérez Ballester \\ Universitat de València ${ }^{1}$ \\ Ángel Velasco Berzosa \\ Arqueólogo, Ajuntament de Xàtiva \\ Reyes Borredá Mejías \\ Arqueóloga \\ José Antonio Rodríguez Traver \\ Arqueólogo
}

Resumen: En este trabajo se exponen los resultados de las excavaciones entre 2006 y 2017 llevadas a cabo en La Solana del Castell (Xàtiva). Se describen las fases de ocupación del lugar desde el Bronce Final hasta la llegada de Roma, con el conflicto entre Pompeyo y Sertorio (siglo I a.C.). Se hace hincapié en la evolución urbanística y sus cerámicas, que revelan un intenso intercambio comercial con las regiones vecinas y el Mediterráneo a lo largo de diez siglos, en el solar de lo que fue la antigua Saitabi.

Palabras clave: Bronce Final, cerámicas, urbanismo, Saitabi.

\section{"La Solana" of the Xàtiva Castle from Prehistory to the arrival of Rome}

Abstract: In this paper we are presented the results of archaecological excavations conducted in La Solana del Castell (Xàtiva) between 2006 and 2017. The phases of occupation of the site are described from the Late Bronze Age until the arrival of Rome, with the conflict between Pompey and Sertorius (first century B.C.). Emphasis is placed on urban development and its ceramics, showing an intense commercial exchange with the Mediterranean Sea and nearby regions over ten centuries on the site of ancient Saitabi.

Key words: Late Bronce Age, Ceramics, Urbanism, Saitabi.

La actual ciudad de Xàtiva se dispone en la vertiente noroeste de la llamada Serra del Castell, coronada por una larga cresta caliza que ha sido utilizada desde las épocas más antiguas como referencia defensiva, alrededor de la cual

Data de recepció: 14 d'abril de 2020 / Data d'acceptació: 20 de maig de 2020.

${ }^{1}$ Departament de Prehistòria, Arqueologia i Història Antiga, Grup de Recerca d'Arqueologia del Mediterrani (GRAM). 
se han establecido diferentes fortificaciones o castillos de los que únicamente nos quedan restos de época islámica y sobre todo de los siglos XVI-XVIII, que son los que hoy día pueden visitarse. De hecho, salvo ligeras referencias a la Saitabi ibérica, con el increíble episodio de la retención allí de Imilce mujer de Aníbal (Silio Itálico, Punica 371), la información que se pone a disposición del visitante no menciona nada anterior a la ocupación árabe.

Y sin embargo, tanto la cresta donde se ubican hoy el Castell Mayor y el Castell Menor, como las dos laderas del mismo: La Costa y La Solana, fueron lugares ocupados por poblaciones muy antiguas, al menos desde finales del segundo milenio antes de nuestra era.

Su ubicación fue fundamental, pues, ofrecía a sus habitantes una protección natural en altura y el control de los diferentes pasos naturales: el camino a las planicies litorales siguiendo el curso del río Albaida hacia la desembocadura del Xúquer, el paso a la Meseta por la Vall del Cànyoles y hacia la Vall d'Albaida por l'Estret de les Aigües.

\section{LA SOLANA, TESTIMONIO DE LA VIDA DEL CASTELL DESDE LA PREHISTORIA HASTA LA OCUPACIÓN ROMANA}

La ladera sur del Castell (La Solana), despoblada desde la segunda mitad del s. I a.C., se desforestó con el transcurso del tiempo y la erosión dejando a la vista la roca natural del monte en parte de su superficie, en especial en los últimos dos siglos. Sin embargo ha conservado algunas zonas con buena acumulación de sedimentos antiguos gracias a la construcción de muros de piedra seca que aterrazan la ladera para permitir el cultivo de almendros, olivos o algarrobos. Aprovechando estas áreas, situadas hacia la mitad de la ladera en la vertical del Castell Menor, hemos documentado a lo largo de diez campañas de excavaciones la continuidad de un hábitat antiguo, que se extiende desde los últimos momentos del Bronce Final (s. X-IX a.C.) hasta el s. I a.C. (Fig. 1).

\section{El Bronce Final}

El Bronce Final en el territorio valenciano (Gil Mascarell 1981, Martí y De Pedro 1997, Hernández 2005, Vives Ferrándiz 2006), va a suponer muchas novedades con respecto a fases anteriores del segundo milenio, las denominadas como Bronce Tardío y Bronce Medio o Bronce Valenciano. Se abandonarán los lugares altos, las cimas, y aparecerán nuevos asentamientos esta vez en las laderas de los cerros, siempre bien situados cerca de vías de comunicación. 


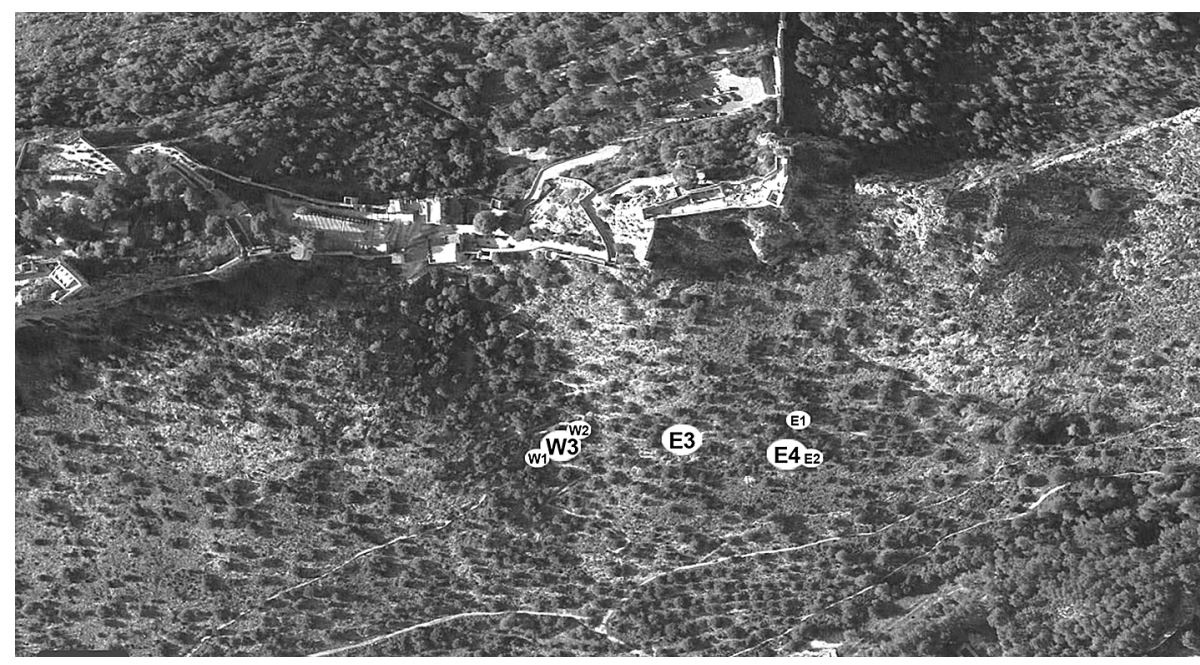

Figura 1. La Solana del Castell. Ortofoto del Castell Menor y sectores de intervención arqueológica. En mayor tamaño, los más desarrollados.

Encontramos en ellos materiales que denotan contactos e intercambios muy variados: con la Meseta (Cultura de Cogotas), Valle del Ebro, Cataluña (Cultura de los Campos de Urnas) y Andalucía. Además desde el inicio del periodo se detectan una serie de elementos manufacturados de origen ultramarino tanto en áreas costeras como en grandes centros del interior, que nos hablan de contactos con gentes mediterráneas (Cerdeña, Sicilia, Mediterráneo Oriental) antes de la llegada continuada y el asentamiento de gentes fenicias en las costas de la península Ibérica. Se trata de objetos exclusivos de adorno personal y panoplia guerrera, como fíbulas o broches de bronce, brazaletes, peines y botones de marfil y algún objeto de hierro manufacturado, como el pomo y el brazalete de hierro del Tesoro de Villena; cuentas de collar de fayenza egipcia y de pasta vítrea, hachas de bronce con apéndices laterales, etc. Estos contactos mediterráneos continuarán hasta finales del periodo, cuando comenzarán a llegar ánforas de vino y copas para servirlo, de origen fenicio o incluso griego. En el caso de La Solana, encontramos un brazalete de marfil, una cuenta de ámbar y una fíbula de pivote entre otros objetos singulares (Pérez Ballester et al. 2011). 


\section{El Bronce Final en La Solana del Castell}

Los primeros resultados sobre restos antracológicos facilitados por Elena Grau (Pérez Ballester et al. 2008: 241-242) pertenecientes a niveles del Bronce Final de la campaña de 2007, nos presentan un paisaje dominado por un bosque abierto de carrasca o coscoja (Quercus ilex/coccifera), madroños (Arbutus unedo) y algunos pinos, con un sotobosque de acebuches (Olea europea) y lentiscos (Pistacia lentiscus); un paisaje similar al que existía en entornos como los que Cavanilles, a finales del siglo XVIII, describía para municipios de Moixent y La Font de la Figuera en la cabecera del río Cányoles (Pérez Ballester y Borredá 1998: 136-137). En La Solana hemos diferenciado dos fases (I y II) para este periodo.

Las estructuras documentadas en la Fase I son testimoniales. Encontramos parte de un murete de tapial y las bases de dos postes colocados a 2,5 m uno de otro sobre una nivelación natural de la roca del monte. Formarían parte de una cabaña alargada en donde los dos postes sostendrían una viga central longitudinal, y el murete compartimentaría parte del espacio interior. También pertenecen a esta fase los rellenos sobre los que se asientan los distintos tramos de la muralla y que forman las terrazas. La cerámica está realizada a mano y tipológicamente sus formas que se acercan a las que encontramos en otros yacimientos del Bronce Final del área valenciana, en especial en La Peña Negra (Crevillent) (Ortiz Temprado 2014). Esta primera fase del yacimiento está datada por C14 sobre dos restos óseos de ovicaprinos: $2740 \pm 30 \mathrm{BP}(\mathrm{Cal}$. BC 930/820) y $2640 \pm 30 \mathrm{BP}(\mathrm{Cal}$. BC 830/790) Beta Analytics 2013 (Pérez Ballester 2014a: 24).

En cuanto a los materiales, las cerámicas a mano ${ }^{2}$ que caracterizan el Bronce Final de la Fase I no son muy distintas de las que encontraremos luego en la Fase II, con algunas excepciones: en la Fase I aparece la única copa con pie alto documentada y el único carrete o soporte del yacimiento, frecuente en el Bronce Final andaluz y del sureste peninsular. Igualmente, a la Fase 1 pertenece un fragmento de olla bitroncocónica, con decoración de acanalados gruesos horizontales, una forma característica de los Grupos de Campos de Urnas Antiguos y Recientes del área catalano-aragonesa. Entre la cerámica de mesa de factura cuidada, a menudo bruñida, son frecuentes los cuencos simples de casquete esférico.

2 Todas las referencias de las formas de la cerámica a mano, pueden consultarse en Pérez Ballester, J.: "Entre el Bronce Final y el Hierro Antiguo. Las cerámicas a mano de La Solana del Castell (Xàtiva, València)”, Lucentum XXXIII, 23-40, 2014. 
La vajilla está formada mayoritariamente por pequeños vasos para beber (cuencos carenados), a veces decorados con motivos incisos: en forma de damero, rombos rellenos de líneas paralelas, zig-zag y triángulos colgantes rellenos de trazos paralelos (Fig. 2). La decoración pintada, de amplia tradición desde el Neolítico, se refleja en restos de pintura roja que ocuparía toda o gran parte de la pared del vaso, sin que se hayan detectado bandas u otros motivos. Otros cuencos menos profundos y mayores, cazuelas carenadas y fuentes, podrían servir para comer y presentar alimentos. Algunas grandes vasijas profundas con tratamiento cuidado son perfectas para contener y conservar agua, y otras de grandes paredes verticales, para contener líquidos pero también cereales o leguminosas.

Las cerámicas toscas son tanto de mesa (minoritarias) como de cocina y almacenaje. Estas últimas se caracterizan por su gran tamaño, y cuello rectos exvasados o bien cilíndricos. Aparecen las primeras ollas de borde recto reentrante y de borde vuelto o estrangulado, frecuentes en fases posteriores. Todas presentan bases planas, a menudo con reborde o talón y en algunos casos presentan por el exterior la impronta de la esterilla de esparto sobre la que realizó.

La fase II presenta un urbanismo bien desarrollado en la parte media de la ladera del Castell Menor, aunque no sabemos cuánto se extendía también hacia la cima, dada la ausencia de sedimentos por la erosión que ha dejado a la vista la roca natural con una fuerte pendiente. Es inmediatamente posterior a Solana I, ya que las dataciones radiocarbónicas son muy similares. Las dos analíticas realizadas sobre muestras óseas de ovicaprinos procedentes de un nivel de derrumbe de una de las casas absidadas y de un relleno asociado a la misma habitación, arrojan una datación de 2760×30 BP (Cal BC 992/989 y 980/829) y de 2650 \pm 30 (Cal BC 894/870 y 849/790) CNA 2017. Lo mismo podemos decir de las formas y decoraciones de las cerámicas a mano, muy parecidas a las de Solana I (Pérez Ballester, 2014a: 30-32).

Sin embargo, nos encontramos ahora ante un asentamiento complejo, como se deduce de los elementos constructivos asociados: 
-La realización de al menos cuatro terrazas artificiales de 1,5/2m de altura que escalonan la ladera del Castell y permiten ganar superficies horizontales o niveladas (entre 3 y $6 \mathrm{~m}$ ) para construir sobre ellas cabañas o casas más complejas que la documentada en la Fase I (Fig. 3).

-La construcción de una muralla y una torre, situadas a media altura de la ladera, y que encierra a todas las casas que conocemos de las Fases I y II (Pérez Ballester et al. 2011). Esta muralla identificada en al menos una longitud de $90 \mathrm{~m}$, discurre de oeste a este con una anchura constante de $1,5 \mathrm{~m}$. Su configuración es diversa: en su parte más occidental se presenta al exterior como un paramento vertical de piedras de regular tamaño que llega a alcanzar los $2,5 \mathrm{~m}$ de alzado y una longitud descubierta de $17 \mathrm{~m}$ (Fig. 4). Sin embargo su cara interna, regularizada con piedras más pequeñas, solo tiene un metro de altura. Por debajo y al interior, encontramos un relleno bien compactado en el que se recuperaron cerámicas a mano de la Fase I del yacimiento. Parece pues que esta muralla tiene una doble función: por una parte como un imponente muro defensivo que no descartamos que estuviese rematado con un alzado de tapial o adobes ${ }^{3}$ y por otra como el muro de contención de una terraza de grandes dimensiones.

En el tramo oriental de unos $12 \mathrm{~m}$ de longitud, la muralla tiene un alzado de solo $1,3 \mathrm{~m}$ y apoya sobre un escarpe rocoso casi vertical, que acentúa la protección, o sobre un talud de tierra (Fig. 5). Por el interior, la configuración es idéntica a la que vimos en el tramo occidental y sus rellenos sirven de plataforma para una de las casas absidadas (Fig. 6). En este sector oriental, la altura conservada desde la base hasta la hilada más alta de la muralla es de 4,46m, dando a este sector un carácter monumental, acentuado por la presencia de la torre.

La torre es un bastión macizo, con unas medidas de $6 \mathrm{~m}$ de frente y $3,50 \mathrm{~m}$ de lado. En la parte delantera hay tres hiladas de grandes piedras irregulares, algunas realmente enormes en las esquinas $(1,30$ x $0,60 \mathrm{~m})$ con un alzado máximo conservado de $1,80 \mathrm{~m}$. Uno de los lados se escalona adaptándose a la roca con una fuerte pendiente y el otro se adosa al talud de tierra (Fig. 7). Su parte superior coincide con la parte conservada de la muralla.

Su función es ambivalente; estamos ante un contrafuerte o refuerzo del terraplén, justo en el punto en el que este coincide con la pendiente de roca natural; y también ante un bastión de muralla de funcionalidad defensiva y sobre todo de prestigio: quien se acercara al asentamiento forzosamente debía pasar junto a él, para acceder a la entrada al poblado que, según las carriladas conservadas en algún tramo, estaría situada unos $50 \mathrm{~m}$ más hacia el este.

3 Posiblemente tapial; hasta el momento sólo se han detectado fragmentos de adobes en dos estructuras pertenecientes a la Fase III, del Hierro Antiguo. 


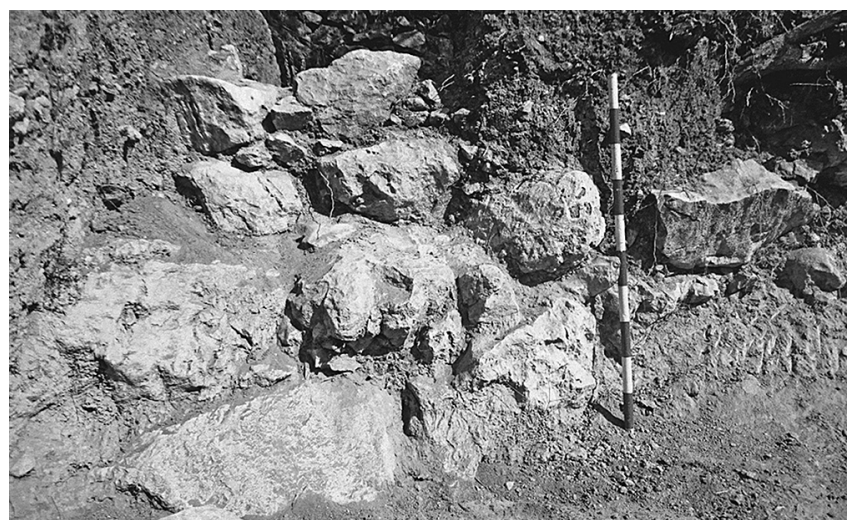

Figura 3. Frente de terraza. La Solana, Sector E4, Fase II.

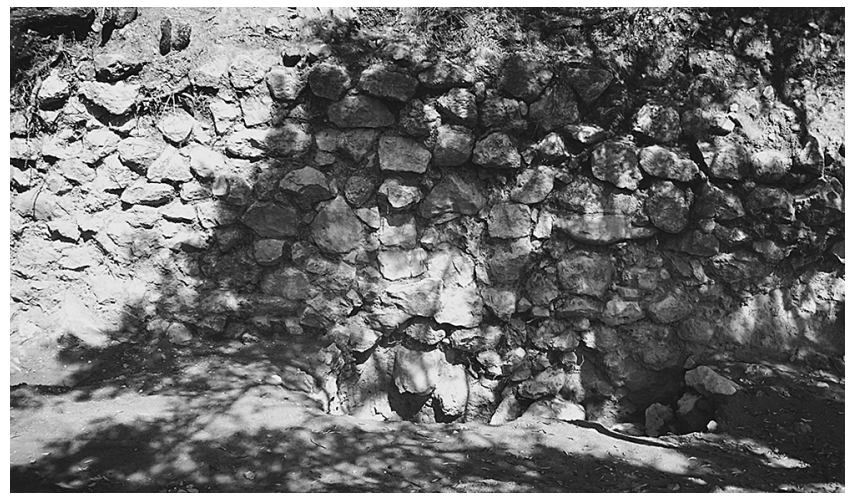

Figura 4. Muralla en el Sector W3. Fase II.

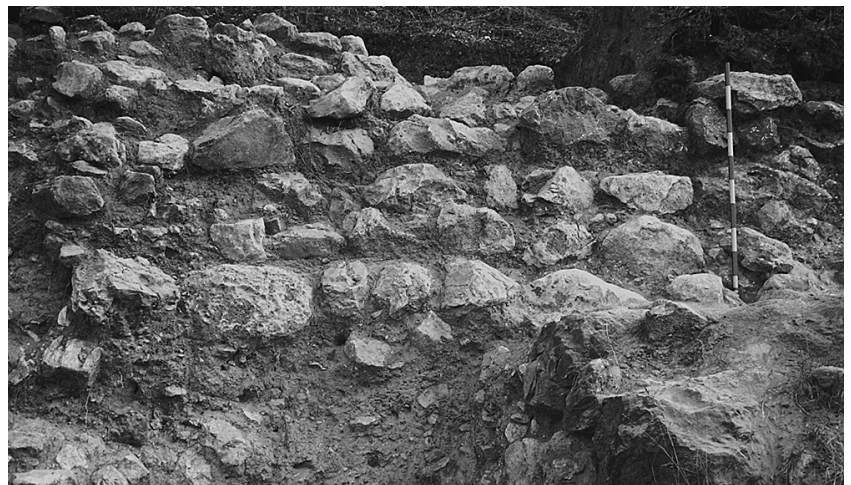

Figura 5. Muralla en el Sector E3. Bajo el jalón, la torre. Fase II. 


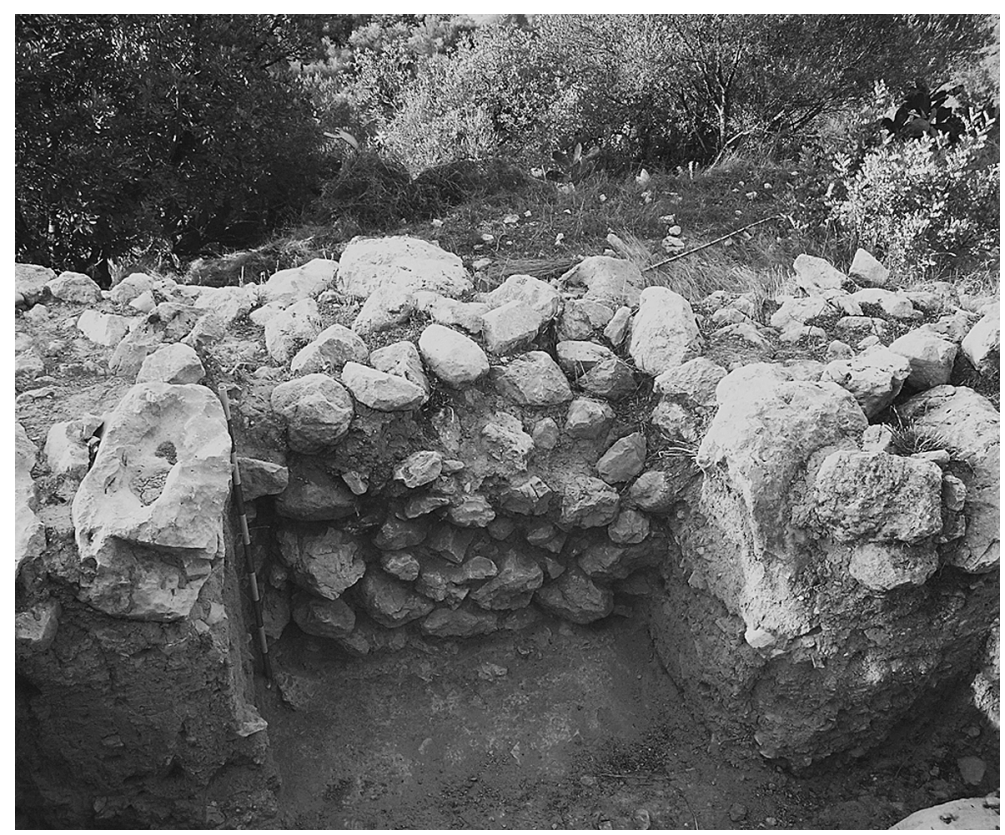

Figura 6. Interior de la muralla en el Sector E3. Fase II.

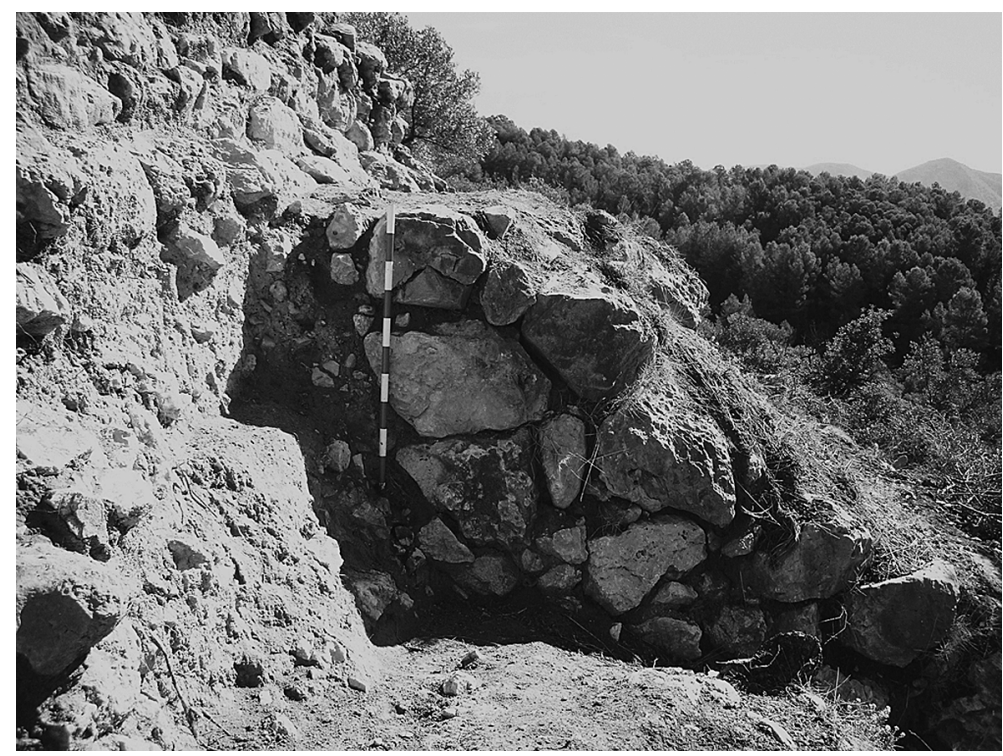

Figura 7. Lado oeste de la torre, apoyada sobre talud de tierra. Fase II. 


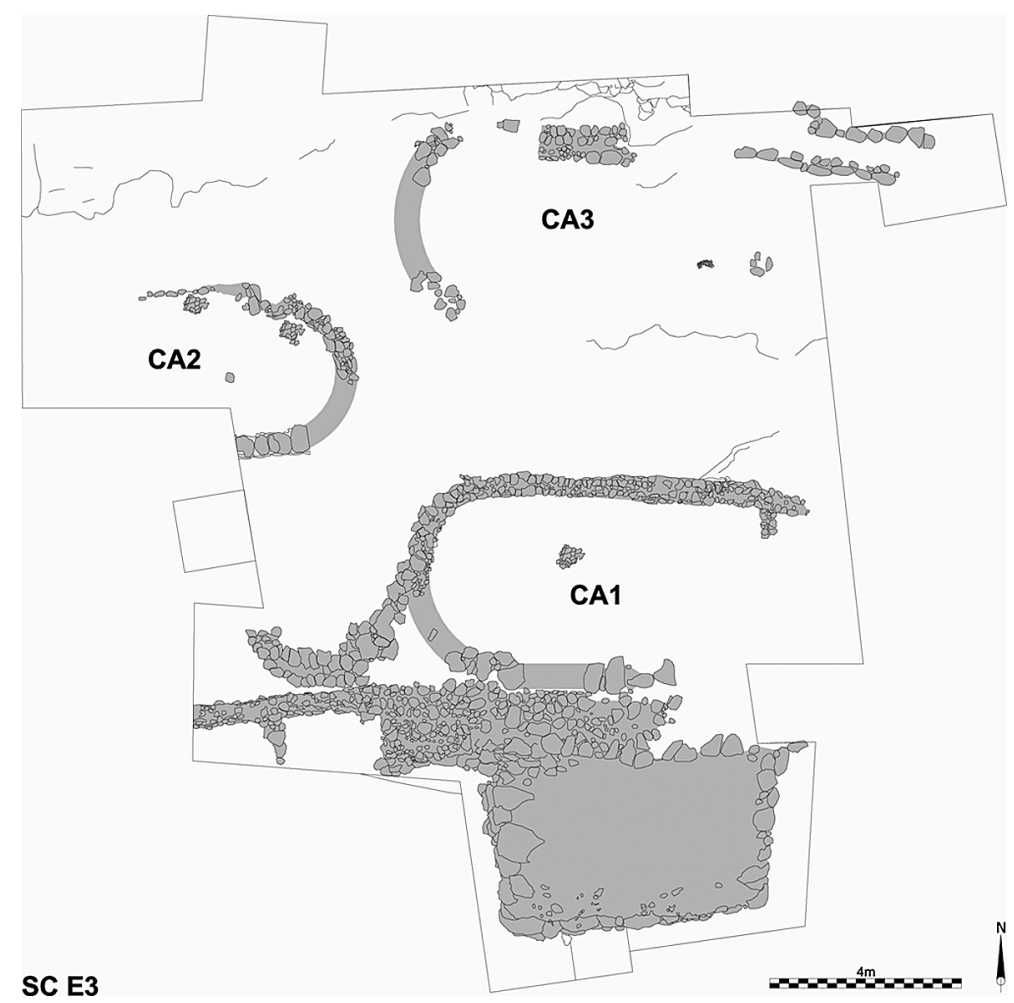

Figura 8. Sector E3. Planta de las tres casas absidadas conservadas. Abajo, la muralla y la torre.

-Casas absidadas (Fig. 8). En el sector oriental, protegido por la muralla y la torre mencionadas, en un espacio de unos $25 \mathrm{~m}$ de longitud por $15 \mathrm{~m}$ de fondo, hemos podido excavar tres casas absidadas relativamente próximas entre sí, pero construidas sobre distintas terrazas de aproximadamente $1,30 \mathrm{~m}$ de altura cada una ${ }^{4}$. Si extrapolamos estos hallazgos a la totalidad del espacio limitado por la muralla, podríamos hablar de la existencia en este poblado del Bronce Final y luego del Hierro Antiguo de al menos 13 o 14 casas de este tipo. Su estado de conservación no es bueno, debido a la fuerte erosión y a la presencia de terrazas modernas que las cortaron longitudinalmente.

${ }^{4}$ Véanse casas 1 y 3, en Pérez Ballester et al. 2013. 
No obstante podemos definir sus principales rasgos. Se trata de tres espacios, definidos cada uno de ellos por dos muros rectos y paralelos que conectan mediante otros dos tramos semicirculares más cortos.

Los muros están formados por un zócalo de piedras de entre 40 y $60 \mathrm{~cm}$ de anchura y aproximadamente $0,50 \mathrm{~m}$ de alto aunque en una de ellas llega a $1,20 \mathrm{~m}$ según la orografía del terreno. Se completarían con un alzado de tapial como indican las gruesas capas anaranjadas caídas, aunque en algún caso hemos detectado posibles fragmentos de adobes. El tamaño de estas casas es variable, entre 7 y $11 \mathrm{~m}$ de longitud con una anchura uniforme de $3 \mathrm{~m}$. Al menos en uno de los casos se conserva parte de un banco corrido adosado a uno de los lados largos; en otra un murete que parece compartimentar el espacio cerca de la entrada. Entre los hogares destacamos uno más grande $(0,90 \times 0,90 \mathrm{~m})$ delimitado por un círculo de conchas marinas (Glicymeris violacescens) muy deteriorado. En otros casos son de menor tamaño: 0,55 x 0,30m, 0'40 x 0'40m, siempre oblongos o circulares.

Un detalle interesante, que nos indica cuál sería su aspecto exterior, es el hallazgo in situ en una de ellas de un pie de poste de piedra, situado justo en el centro de la semicircunferencia que define el lado curvo de la casa. Nos está indicando un sistema de cubrición formado por dos o tres puntales verticales que sostienen una viga longitudinal (tejado a dos aguas) y otras pequeñas vigas radiales que parten del puntal apoyado en la base documentada hacia el extremo superior de la pared curva, al estilo de cabañas bien conocidas desde el periodo Vilanoviano itálico, en el mundo griego y en momentos algo posteriores, en el sur de Francia (García y Trézigny 2010; Nickels 1989) (Fig 9). Los paralelos más cercanos los encontramos en el Torrelló del Boverot (Almassora), con casas absidadas tanto en la fase del Bronce Final como en la de transición de Bronce Final a Campos de Urnas (Clausell 2004).

La presencia en algún caso de varios pavimentos superpuestos nos indica una larga utilización de estas casas. También hay que decir que al menos una de ellas solo presenta ocupación ya en el Hierro Antiguo, época en las que constatamos que las tres estaban ocupadas.

En cuanto a las cerámicas de esta Fase II las más frecuentes entre las cuidadas siguen siendo los cuencos y fuentes carenados, aunque en menor proporción que en la fase anterior. Las técnicas utilizadas en la decoración de los vasos son las mismas de la Fase I. Se utilizan acanalados profundos y otros apenas marcados, incisión y pintura, esta última técnica muy escasa. Los motivos más frecuentes entre las incisas, son ahora los triángulos rellenos de líneas paralelas (Fig. 10).

Entre las cerámicas toscas son numerosos los cuencos simples y destaca el aumento de las ollas, que serán tan abundantes en el Hierro Antiguo. La mayor 


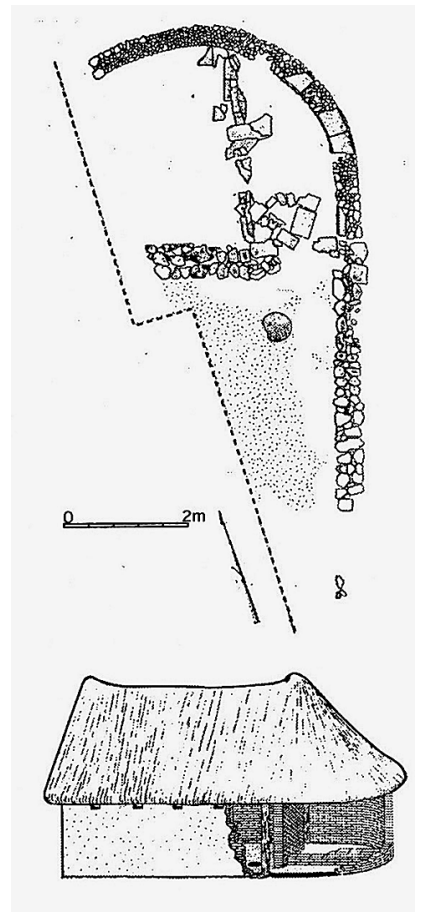

Figura 9. La Monedière (Bessan, Hérault). Casa absidada y reconstrucción (Nickels, 1989).

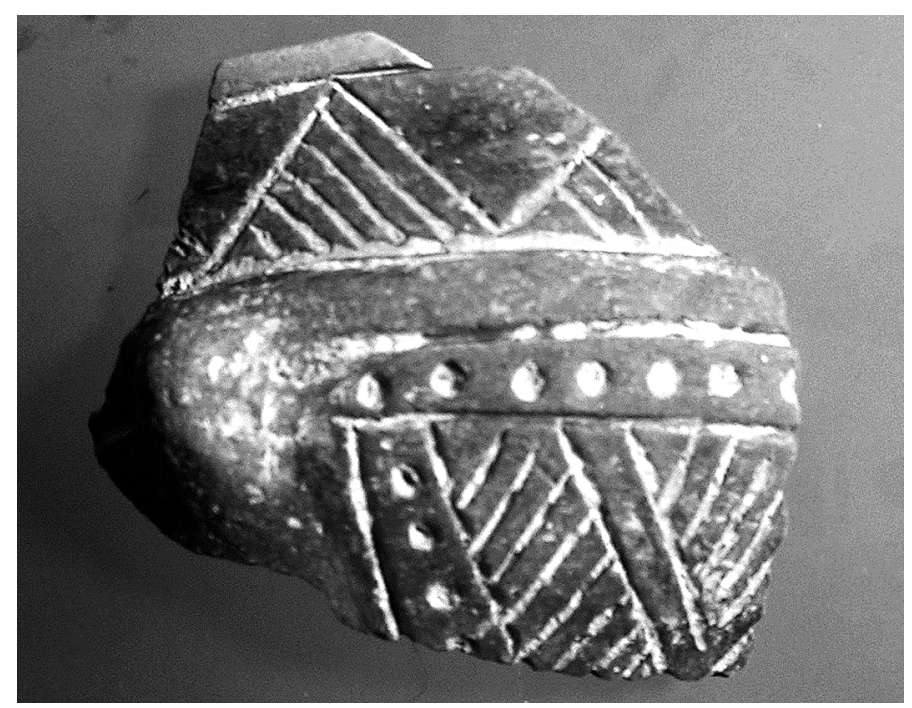

Figura 10. Cuenco carenado con decoración incisa. Fase II. 
cantidad de estos recipientes parece indicar una sustitución progresiva de los grandes contenedores por otros de menor tamaño y con bocas más pequeñas, muchos de ellos preparados para recibir tapaderas, más adaptados a la cocción de alimentos aunque no hemos encontrado trazas claras de este uso entre las piezas estudiadas.

\section{El Hierro Antiguo o la Primera Edad del Hierro}

En tierras valencianas, este periodo se extiende desde finales del siglo VIII a la primera mitad del VI a.C. (Vives Ferrándiz 2006; Hernández 2005: 24-25; González Prats 1985, 2011 y 2014) y está directamente relacionado con la presencia, física o comercial, de gentes fenicias occidentales que aportarán una serie de novedades tecnológicas a las gentes del Bronce Final.

Por lo que se refiere a los asentamientos, encontraremos una continuidad de los hábitats del Bronce Final, como veremos que ocurre en La Solana del Castell de Xàtiva; pero aparecerán también otros nuevos en la línea de costa, en relación con la presencia directa o indirecta de gentes fenicias occidentales: La Fonteta (Guardamar, Alicante) y Alt de Benimaquia (Dènia, Alicante) y lugares de contacto e intercambio como el que debió existir en el Altet de la Vintihuitena (Albalat de la Ribera), entonces muy próximo a la desembocadura del Xúquer.

A nivel cultural, los cambios son muy importantes: introducción de la metalurgia del hierro; estructuras urbanas complejas frente a las cabañas ovales o circulares anteriores; uso del torno para la fabricación de cerámica; el cultivo de frutales: vid, olivo, almendro y el aumento del ganado estabulado, ovicaprinos principalmente, pero también bovinos (Iborra 2004). En cuanto al comercio, es frecuente la presencia de cerámicas importadas de origen fenicio occidental: ánforas de vino, tinajas o pithoi, morteros trípodes, vajilla de mesa de barniz rojo o grises, cerámicas pintadas, fíbulas de doble resorte, etc., que encontramos hasta $100 \mathrm{~km}$ al interior (Vives Ferrándiz 2006: 149-159).

Como dice Rodríguez Traver (2008: 258): ...esta interacción cultural entre el mundo fenicio y las comunidades peninsulares supondrá un importante estímulo económico, tecnológico y cultural para las sociedades indígenas y constituirá un factor fundamental en el desarrollo de estos pueblos ya que acelerarán un proceso de transformación de las sociedades indígenas hacia estructuras socio-políticas y económicas más complejas que en último término desembocará en el surgimiento de la Cultura Ibérica... Pero sin lugar a dudas uno de los fenómenos más importantes que se desarrolla en este momento es la aparición de territorios autónomos con una estructura de hábitat claramente jerarquizada y organizada en torno a un gran asentamiento de carácter protourbano que ejerce 
como "lugar central" dentro del poblamiento zonal. En nuestro caso, es El Castell de Xàtiva, identificado con la futura ciudad ibérica de Saitabi, el yacimiento que parece erigirse en centro nuclear del poblamiento comarcal.

\section{El Hierro Antiguo en La Solana}

El paisaje que nos proporciona el estudio preliminar de los restos antracológicos pertenecientes a este periodo, no difiere demasiado de lo observado para el Bronce Final. Si acaso, destaca en el sotobosque la presencia de boj (buxus) y romero (Rosmarinus officinalis) junto al olivo/acebuche (Olea europea) y el lentisco (Pistacia lentiscus) (Pérez Ballester et al. 2008: 241-242).

Desde el punto de vista cultural, es ahora cuando se hace evidente el contacto entre la población local y las gentes que llegan por mar, con la presencia de cerámicas a torno de origen fenicio occidental, que llega a porcentajes cercanos al 10/12\% del total. Se trata en su mayoría de ánforas de vino, pero también hay un importante porcentaje de vajilla de barniz rojo y cerámica común fenicia, entre la que destacan los platos y los cuencos trípodes. Se constata el conocimiento de la metalurgia del hierro, con el hallazgo de restos de escoria y algún pequeño objeto no identificable. En lo que se refiere a los restos de fauna, vemos un aumento en la cabaña de ovicaprinos con respecto a niveles anteriores del Bronce Final.

La cronología de esta fase III no se ha basado en dataciones absolutas. Los análisis de C14 sobre una muestra de colágeno de ovicaprino nos ha proporcionado lo que es habitual en los registros radiocarbónicos referidos a los siglos VIIIVII a.C. en la península Ibérica: una meseta que comienza en el 771 y acaba en el 478 BC (medición Cal 2 sigma, CNA 2017), lo que no es del todo negativo, pues la cronología relativa que proporcionan las cerámicas fenicias nos ayuda a fechar estos niveles del Hierro Antiguo en el siglo VII a.C.

En esta fase se ocupan dos de las casas absidadas quizás construidas en estos momentos, pues en ellas no encontramos un nivel de habitación claro del Bronce Final.

Ya comentamos que la torre, al estar construida en un momento posterior a la muralla, podría ser también de esta época, aunque no tenemos confirmación arqueológica clara de que así sea.

Más hacia el este (Sector E4) hemos excavado nuevas estructuras de habitación en otras terrazas levantadas al exterior de la muralla:

-Un espacio ovalado, de 4 x 1m (Fig. 11), adosado a una terraza superior, con restos de una zona de combustión, con cerámicas a mano y a torno fenicias. 
-En un nivel inferior, $3 \mathrm{~m}$ más abajo de la anterior, una habitación apoyada en la roca natural, con parte de un muro que cierra un espacio de $4 \times 2 \mathrm{~m}$. Tiene claros restos de adobes, un área de combustión y cerámicas a mano y a torno fenicias. Está cortada longitudinalmente por una terraza moderna, y su tamaño podría ser el doble que el conservado.

Entre la cerámica de esta fase de Hierro Antiguo, debemos distinguir ahora entre aquellas a mano de las realizadas a torno, de origen fenicio occidental. Las cerámicas a mano cuidadas, bruñidas en su mayor parte, ofrecen un panorama algo distinto del que observábamos para el Bronce Final. Son aún frecuentes las copas carenadas y los pequeños cuencos para beber; hay algunas formas nuevas de fuentes, con bordes aplanados ondulados o lisos, habituales en niveles del Hierro Antiguo de la Peña Negra (Crevillente), que seguirán luego en el Ibérico Antiguo. La técnica decorativa más abundante es la incisión y el motivo principal de series de triángulos rellenos de líneas paralelas como en la Fase II. El uso de la pintura roja es habitual y aparece por primera vez el grafitado. Esta técnica, es frecuente en la Meseta ya en s. IX (Barroso Bermejo 2002: 137-139) y su aparición más al sur se documenta en Cástulo (Jaén), donde se fecha entre finales del s. VIII y el s. VII. En nuestro territorio, está documentada con la misma cronología en lugares como Los Villares de Caudete (Mata Parreño 2019: 45-48) donde es el recurso decorativo más utilizado.

Entre las cerámicas toscas, las ollas de borde reentrante y las de borde exvasado constituyen ahora más del $50 \%$ del total, certificando la importancia de estos recipientes tan frecuentes en asentamientos del Hierro Antiguo entre los ríos Xúquer y Segura. Las de borde reentrante (Fig. 12) son las mismas que se documentan en el área murciana y granadina con el nombre de orzas. Parece ser que sustituyen a los grandes recipientes, ahora muy escasos. Es posible que nos encontremos ante un cambio de hábitos culinarios, seguramente con una mayor atención a las cocciones de alimentos y a un almacenaje variado y más selectivo.

Las cerámicas a torno de esta fase se refieren como ya hemos comentado a importaciones fenicias occidentales 5 . Representan, en número mínimo de individuos (NMI) un porcentaje del $8 \%$ en contextos de la Fase III. Si tenemos en cuenta otras piezas halladas en niveles revueltos, mezclados o superficiales, estas cerámicas llegan al 10/12\% del total. Destacan especialmente las ánforas de transporte (NMI: 21 ejemplares) (Fig. 13) pero también cuencos y platos de barniz rojo o grises (NMI: 22 ejemplares). Una jarra de boca trilobulada y recipientes cerrados distintos a las ánforas, entre los que se encuentran algunos phitoi, completan el repertorio junto a otros pequeños bordes de forma no identificada.

\footnotetext{
5 Actualmente en estudio por J.A. Rodríguez Traver y yo mismo.
} 


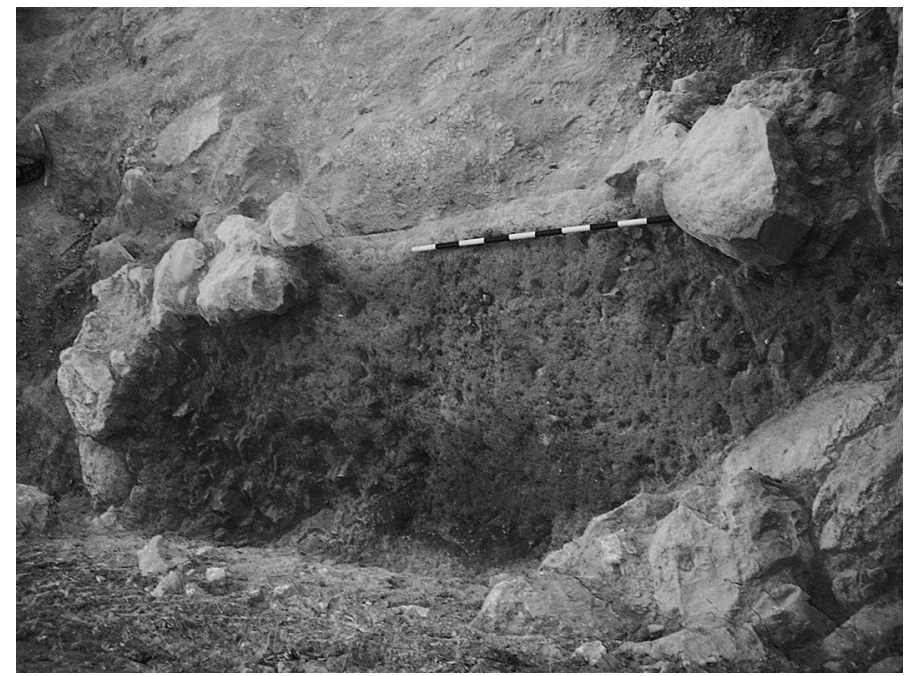

Figura 11. Estructura ovalada adosada a una terraza en E4. Fase III.

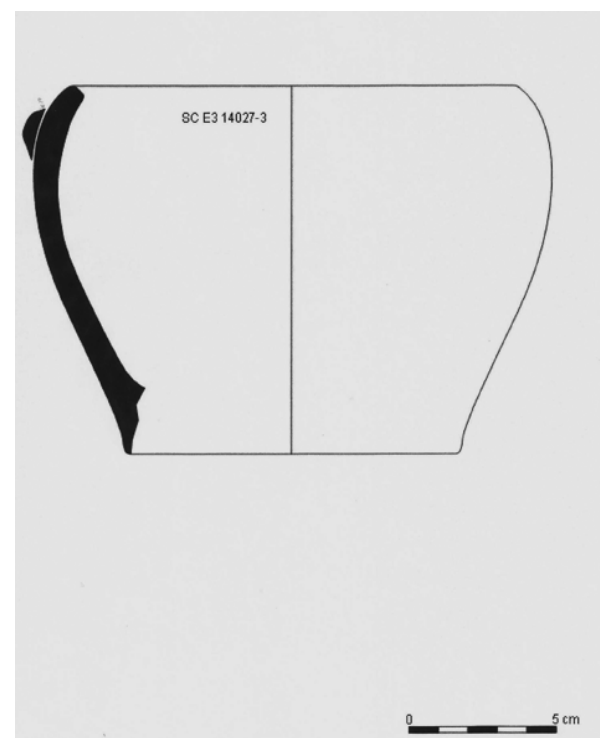

Figura 12. Olla borde reentrante, T-IV-1. Fase III.

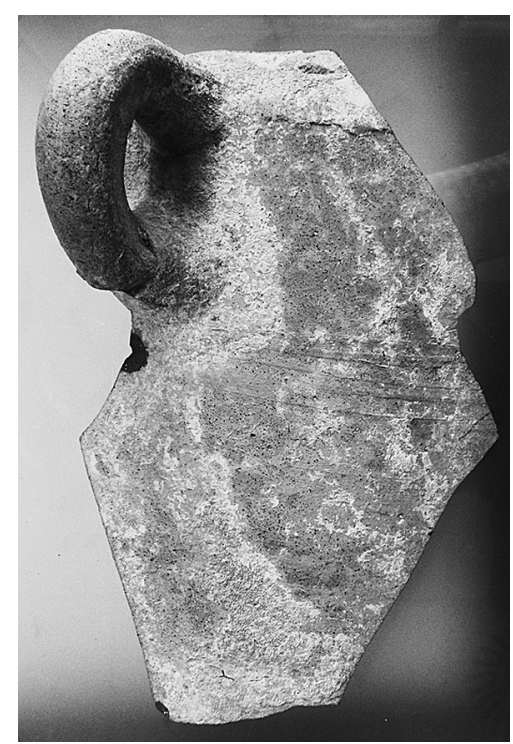

Figura 13. Ánfora fenicia occidental, tipo R-1 / T-10.1.2.1. Habitación absidada 2. Fase III. 


\section{El asentamiento ibérico}

En La Solana del Castell, por encima de las estructuras murarias del Bronce Final y el Hierro Antiguo ya expuestas, encontramos otras más recientes. Las asociamos a un hábitat de época Ibérica, la antigua Saitabi, posiblemente el lugar central y la capital de un amplio territorio en el periodo Ibérico Pleno que limitaba al Norte con el valle del Xúquer, al Este con las sierras de Requena, Buixcarró y Marxuquera, al Sur y Sureste con las sierras d'Agullent y Benicadell, y al Oeste con el macizo del Caroig. Englobaba las actuales comarcas valencianas de La Canal de Navarrés, La Costera de Ranes llegando hasta La Font de la Figuera, y la mitad Nordeste de la Vall d'Albaida, haciendo un total aproximado de $950 \mathrm{~km}^{2}$ (Pérez Ballester y Rodríguez Traver 2008: 281-284).

Cerámicas y muros se detectan por la ladera del Castell Menor, sobrepasando hacia el sur las estructuras más antiguas cubriendo una extensión superior a las 6 hectáreas. Esta ocupación, como hemos expuesto en otro lugar (Pérez Ballester y Borredá 2008: 273-274), se extendería también por la cima de la montaña del Castell y la ladera norte, la Costa, llegando a tener una superficie total cercana a las 20 hectáreas.

\section{El periodo Ibérico Antiguo (desde mitad s. VI a finales s. V a.C.)}

Es la Fase IV de La Solana. Las estructuras de habitación excavadas son más escasas, ya que a menudo sus materiales fueron reaprovechados en momentos posteriores. Reconocemos dos posibles casas en el sector oriental (E-3), levantadas ambas sobre la misma terraza y situadas sobre dos casas absidadas más antiguas. Se trata ahora de habitaciones rectangulares parcialmente conservadas con más de 9,5m de longitud y al menos en un caso 6,5m de anchura. El espacio interno está subdivido por un murete transversal, que delimita dos ambientes. En una de ellas existe un banco corrido adosado a uno de los muros largos y en otra los restos de un hogar.

No es fácil separar los contextos cerámicos pertenecientes a esta fase del Ibérico Antiguo, ya que sus materiales aparecen en niveles arqueológicos con altos porcentajes de cerámicas a mano y también a torno fenicias, así como mezcladas con cerámicas ibéricas más modernas en grandes paquetes de estratos de aluvión, procedentes de la parte alta de la ladera.

Entre las formas ${ }^{6}$, en la vajilla de mesa son frecuentes los platos de borde horizontal en ocasiones con decoración pintada geométrica bícroma (rojo y

${ }^{6}$ La cerámica ibérica de La Solana está en estudio por J.A. Rodríguez Traver. 
negro) y sobre todo los pequeños platos de borde vuelto y cocción reductora (grises). Entre los recipientes de almacenaje, tinajas y tinajillas de borde subtriangular, pithoi con varios pares de asas que imitan a los fenicios y urnas de orejetas perforadas. Entre las decoraciones pintadas, las más frecuentes son bandas anchas horizontales pintadas limitadas por otras muy finas horizontales y paralelas. También series de trazos verticales ondulados y paralelos (melenas) y círculos concéntricos de trazado muy cuidado, realizados a veces a compás.

\section{El periodo Ibérico Pleno - Tardío (s. IV a s. I a.C.)}

Siempre en el sector oriental (E-3) de La Solana se han documentado toda una serie de estructuras (Fig. 14) que nos permiten hablar de un urbanismo ibérico organizado en terrazas, de las que conocemos al menos tres:

T1. Una terraza superior, con tres departamentos definidos y otros dos posibles colocados en batería. Una calle (C1) de 1,1m de anchura y una longitud conservada de $10 \mathrm{~m}$.

T2. Una terraza intermedia con un posible paso o escalera a la terraza superior y su calle $\mathrm{C}-1$.

T3. Y una terraza inferior de la que conservamos muy pocos vestigios.

La documentación de estas estructuras es difícil, dado el nivel de arrasamiento por erosión de la ladera de La Solana; y su conservación no es muy buena, como veremos.

En la terraza T1 nos detendremos en los Departamentos D1 y D2 (Pérez Ballester et al. 2010). Ambos tienen una longitud aproximada de 5m, y una anchura de $2 \mathrm{~m}$ en el primer caso y $3,5 \mathrm{~m}$ en el segundo. Presentan pavimentos de tierra apisonada y endurecida, con unos hogares lenticulares y rubefactados de 60 x $60 \mathrm{~cm}$ de superficie y un grosor de $13 \mathrm{~cm}$.

En el departamento D1 existe un soporte de molino $(60$ x $60 \mathrm{~cm})$ similar a otro hallada en el Departamento 5 del poblado ibérico de Castellet de Bernabé (Llíria), aunque el nuestro no está enlucido (Guérin 2003: 28 y 262-263, fig. 47). En cuanto a los muros, sobre un zócalo de piedra de unos $50 \mathrm{~cm}$ de altura, la erosión ha respetado dos adobes superpuestos de 50 x $10 \mathrm{~cm}$ que nos hablan de cómo estarían construidos los alzados completos de los mismos (Fig. 15).

El lado corto o trasero norte es común a ambos departamentos y está formado por grandes piedras, de $0,50 \mathrm{a} 1 \mathrm{~m}$ de altura y la propia roca natural; podría constituir parte del muro de aterrazamiento de una terraza superior (T4) sobre la que se alzarían otros departamentos.

Al oeste del D1 hemos documentado restos muy dañados por la erosión de otros departamentos que estarían situados igualmente en batería. La parte tra- 


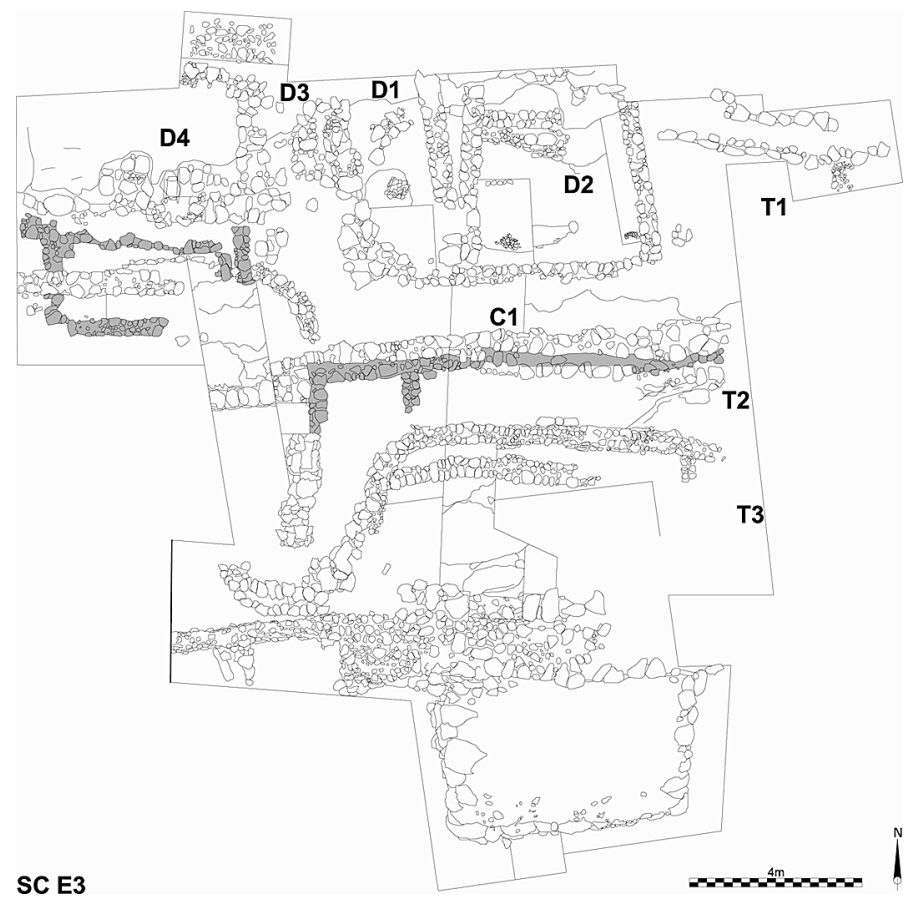

Figura 14. Sector E3. En la mitad superior, estructuras ibéricas. Tramadas en gris, las del Ibérico Antiguo.

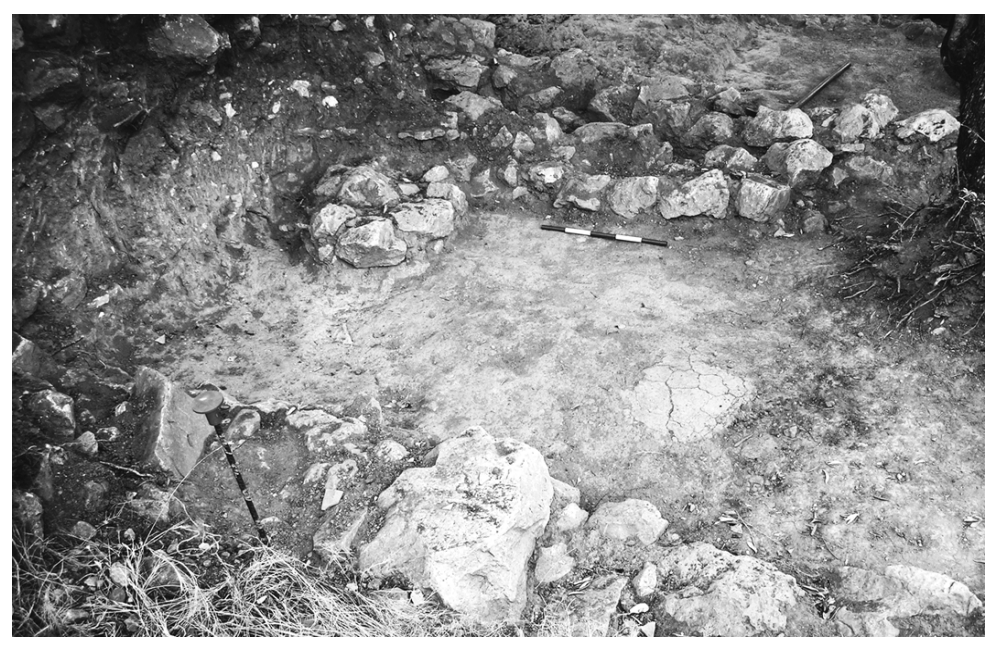

Figura 15. Departamento D1. Base de molino. En primer término, hogar lenticular. 
sera o norte está formada por la propia roca natural, casi vertical en esta zona, rematada por un muro de piedras medianas, que enlaza con la trasera del D1. El primero (D3) tiene una anchura de $2 \mathrm{~m}$ como D1, y su límite oeste es un muro conservado parcialmente. El muro de cierre sur es el mismo que cierra los departamentos D1 y D2 y mide 6m de longitud, por lo que cerraría D3 y el siguiente D4 más al oeste.

De este último destacamos una elaborada base de poste de $28 \times 26 \mathrm{~cm}$, formada por cuatro lajas verticales sobre otra horizontal que nivela la roca natural. Nuestra hipótesis es que formaría parte de la sustentación de la techumbre o de un piso superior de este posible departamento ibérico.

Hacia el sur, otros muros incompletos delimitan pequeños espacios que aprovechan los de los Departamentos D3 y D4, por lo que pensamos corresponden a una fase posterior en el tiempo. En el extremo oeste, cortado por el límite de la excavación, se insinúa otro departamento (D5).

\section{Terraza T2 (Fig. 14)}

A un nivel inferior de los departamentos D1 a D5 que acabamos de ver, hay otra terraza con viviendas de época ibérica. Está separada de T1 por una calle $(\mathrm{C} 1)$ de la que conservamos $11 \mathrm{~m}$ de longitud y una anchura de $1,1 \mathrm{~m}$. Esta calle, en su extremo oeste gira en ángulo recto hacia el sur y parece que permite un acceso de comunicación entre ambas terrazas T-1 y T-2, que podría ser en escalera, aunque ha desaparecido.

Las estructuras ibéricas de esta terraza están muy dañadas por la erosión. Identificamos solo dos muros paralelos separados por una anchura de 2,5m, en disposición similar a la de otros departamentos de la terraza superior. Este espacio contiene un pavimento de tierra apisonada con hogar, sin que podamos añadir nada más sobre su posible compartimentación.

\section{Terraza T3}

Nos hemos atrevido a aventurar la existencia de una tercera zona de habitación del Ibérico Pleno, que estaría situada al sur, en una terraza más baja que T2. El único testimonio del que disponemos es un muro sin conexión física con otros de la misma época, orientación N-S, 2,7m de longitud y un alzado cercano al metro, que está asociado a niveles con cerámicas ibéricas de época plena.

\section{Materiales asociados a estructuras de este periodo Ibérico Pleno-Tardío}

Como hemos mencionado más arriba, las estructuras y niveles arqueológicos ibéricos de los periodos Pleno y Tardío son los más superficiales en el yaci- 
miento y han sufrido especialmente la acción erosiva en la ladera de La Solana del Castell.

Donde los niveles arqueológicos se han encontrado aún in situ, los materiales asociados son muy escasos, debido seguramente al abandono pacífico del lugar.

Mencionamos en la terraza T1, sobre el pavimento del departamento D1, fragmentos aplastados de una gran pátera o tapadera de borde reentrante, una pequeña tapadera de olla de cocina y algunos fragmentos de distintas vasijas decorados con anchas bandas paralelas.

En la terraza T2 hemos hallado un paquete de materiales mezclados con adobes sobre una pequeña superficie de pavimento. Documentamos algunos platos, en su mayoría grises; páteras de borde reentrante; caliciformes y un lebes. La cerámica de almacenaje está representada por algunas ánforas y tinajas, y la de cocina por dos ollas y una tapadera. Algunos vasos áticos de barniz negro: copa/cílica y crateriscos, y otros de barniz negro pero itálicos, completan el panorama de materiales asociados claramente a esta fase. Destacamos, bajo el hogar, un posible depósito de fundación del mismo formado por un vasito caliciforme de 8 x $9 \mathrm{~cm}$ que contenía un anillo de bronce liso (Fig. 16).

Pero en los niveles de relleno antiguos que aparecen por todo el yacimiento, procedentes de zonas superiores de la ladera, así como en los superficiales encontramos el repertorio completo de la cerámica ibérica de la zona:

Entre la cerámica de mesa, platos, páteras, cuencos, caliciformes, jarros y lebetes; tinajillas, tinajas, vasos con pico vertedor, cálatos o ánforas, entre la de almacenaje, y ollas y tapaderas entre la de cocina. Otros objetos como fusayolas, pondera y tejuelos también están presentes.

Las decoraciones que acompañan a muchos de estos vasos ibéricos son preferentemente geométricas, predominando las bandas y filetes paralelos; también son numerosos los cuartos de círculo rellenos y las series de rombos. La decoración compleja de tipo fitomorfo es escasa y aparece representada especialmente en el interior y exterior de platos así como en algunos cálatos y tinajillas. No hemos documentado en las excavaciones motivos figurados animales o humanos, aunque sí entre materiales descontextualizados procedentes del entorno (La Coroneta de Rotglà) y depositados en los almacenes del Museu de Xàtiva (Pérez Ballester y Rodríguez Traver 2008: 327) (Fig. 17).

Junto a estas cerámicas ibéricas encontramos otras importadas: fragmentos de algunos vasos áticos de figuras rojas o de barniz negro (Pérez Ballester 2017) así como cerámicas de barniz negro itálico, ánforas romanas republicanas, vasitos de paredes finas y cerámica común romana, que nos enmarcan estos conjuntos en un amplio arco cronológico entre finales del siglo $\mathrm{V}$ y el siglo I a.C. 


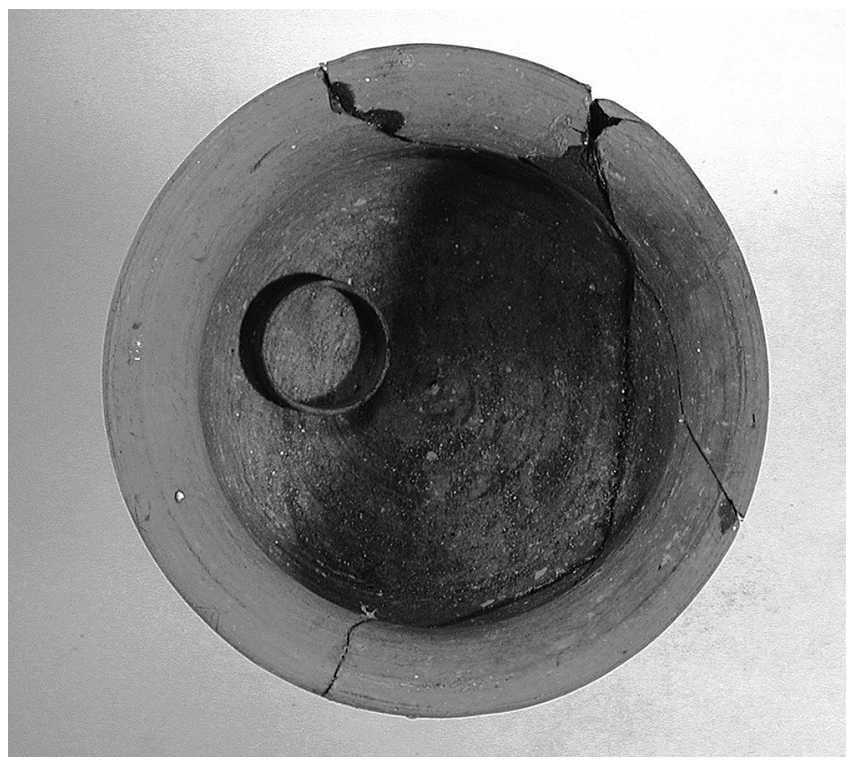

Figura 16. Segunda Terraza. Vasito caliciforme gris y anillo en su interior.

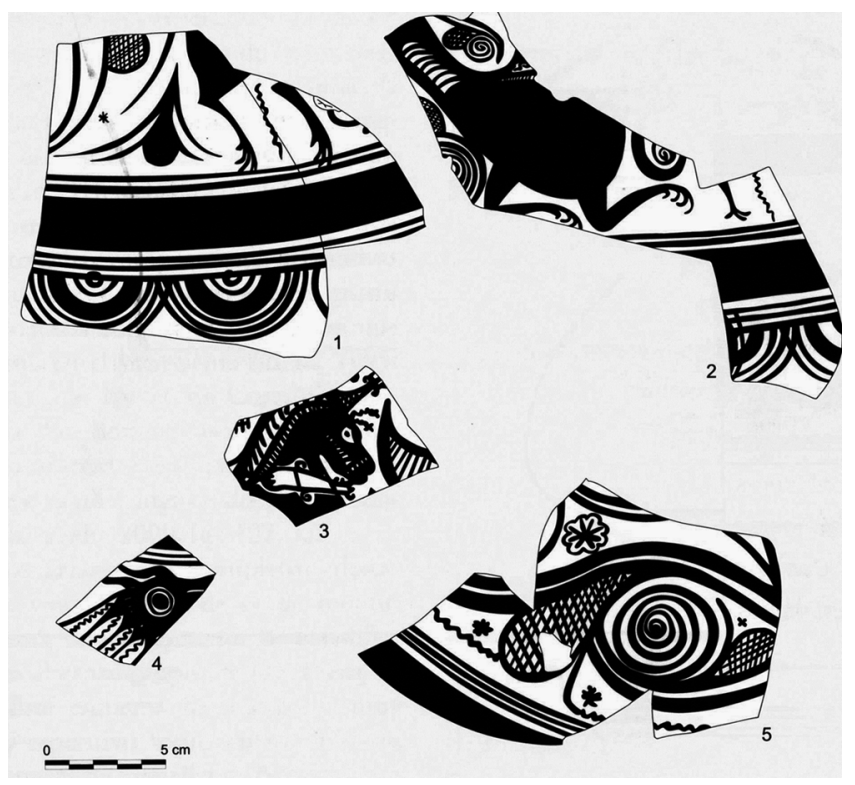

Figura 17. Cerámicas ibéricas con decoración compleja de La Coroneta (Pérez Ballester y Rodríguez Traver 2008). 


\section{La llegada de Roma: Saitabi y Sertorio}

Tras la batalla de Sucro (75 a.C.), librada entre los ejércitos de Sertorio y Pompeyo en las proximidades de la desembocadura del Xúquer y que supuso la derrota casi definitiva de Sertorio en Hispania (Pérez Ballester 2014b), su efecto se dejó sentir en las ciudades ibéricas cercanas.

Las excavaciones arqueológicas en La Solana del Castell determinan que hacia finales del primer cuarto del s. I a.C. hay un abandono generalizado del hábitat ibérico en esta ladera sur del castillo de Xàtiva. A partir de ese momento la población se va a concentrar en la ladera norte y seguramente en su parte más baja, conservando la atalaya que habría en la cresta que hoy ocupa el castillo medieval.

Efectivamente, en La Solana no hemos encontrado materiales de época romana significativos posteriores al primer cuarto del s. I a.C., salvo algunas cerámicas tardorromanas, almohades y altomedievales, que evidentemente han rodado desde la cresta ocupada por los castillos medievales. A la época sertoriana se adscriben fragmentos de ánforas vinarias itálicas tirrénicas y adriáticas; vajilla de mesa de barniz negro campaniense; vasitos de paredes finas y cerámica de cocina itálica. Esta última, si bien alguna podría llegar a época augustea, tal y como se presentan asociadas nos permiten centrarlas en la primera mitad del s. I a.C., pudiendo ser incluso del primer cuarto de ese siglo. En estas condiciones, ánforas de vino, vajilla de mesa de barniz negro y cerámica de cocina itálica nos podrían marcar, como en otros lugares, la presencia o el paso de tropas romanas por el territorio.

Nos detendremos en la cerámica de cocina itálica: unos recipientes que soportan altas temperaturas, preparados para la cocción de alimentos en horno o sobre brasas y no sobre fuego vivo, para cocinar alimentos en caldos cortos o grasas, o bien asados y pudings de nombre patina que identifica al mismo recipiente donde se prepara (Pérez Ballester 2014b: 62). Un modo de cocinar totalmente alejado de las vasijas y usos locales, a los que corresponden las ollas profundas con tapadera para cocciones con abundante agua de legumbres, verduras o carnes; tortas de cereales cocidas en hornos tipo taboun y asados de carnes en espetón.

Estas cerámicas de cocina podrían marcar la presencia de gentes itálicas dentro de asentamientos iberos en este caso en Saitabi, una civitas stipendiaria desde inicios del s. II a.C.; que debió sufrir una deditio tras la batalla de Sucro ya que no se ha detectado la destrucción del oppidum; que comerció abiertamente con los romanos; que posiblemente proporcionó tropas auxiliares a sus ejércitos y que pudo alojar incluso un destacamento militar. Fuera de los asen- 
tamiento ibéricos, otros lugares donde son abundantes estos materiales son los grandes puertos de recepción de tropas y avituallamientos como Carthago Nova o Tarraco, y también en los castra de la época que se han excavado, como Cáceres El Viejo o el campamento V de Renieblas frente a Numancia, fechable en la época de las Guerras Sertorianas?

La evolución de las emisiones monetales de bronce de Saitabi nos ayudan a comprender la situación. P.P. Ripollés en su trabajo sobre la ceca de Saitabi (2007) estima que entre la mitad del s. II y la mitad del s. I a.C. se acuñaron más de un millón y medio de monedas de Saitabi. Aunque llegaron a Lusitania, Valle del Ebro y Emporiae, fundamentalmente tuvieron un área de circulación regional $(80 / 100 \mathrm{~km})$, en la zona delimitada por Saguntum, Valentia, Kelin, Castellar de Meca, Lucentum e Ilici. Dado su bajo valor, servirían como otras cecas ibéricas para popularizar el intercambio monetal frente al trueque. Serían empleadas en pequeñas transacciones personales y en mercados y no como medio de pago de impuestos a Roma, que se haría en plata o en materias primas.

Nos interesan especialmente las emisiones de moneda setabense del Grupo IV, con el tipo claramente ibérico del jinete, fechable entre fines del s. II o inicios del s. I a.C. (Fig. 18); las del Grupo V, con leyenda ibérica, pero con tipos similares a los denarios de L. Lucretius Trio y Mn Cordius, monedas que se consideran acuñadas después del 76 a.C. Y el Grupo VI, última acuñación de la ciudad, ya bilingüe y que se fecha aproximadamente a mediados del s. I a.C. (Fig. 19). Los tres grupos, según Ripollés, presentan una acusada bajada en el número de monedas acuñadas con respecto a las del s. II a.C. (Ripollés 2007: 58-59 y 105-106).

Nosotros interpretamos que el Grupo IV representaría aún cierta autonomía de la ciudad de Saitabi en la decisión de uso de tipos propios que la identifican, antes del conflicto sertoriano; el Grupo V implicaría una posible imposición o reconocimiento de la fuerza de la moneda romana, en un momento delicado que presupondría el apoyo de Saitabi a la fallida causa sertoriana. El Grupo VI nos habla de una nueva situación en la comarca, en la que ciudades como Saitabi pero también otras del entorno como Kili (La Carència) acuñan moneda bilingüe, en el marco histórico de la presencia cesariana y su influencia en los cambios de estatus de muchas ciudades ibéricas de Hispania.

En cuanto a la posible influencia del conflicto sertoriano en los oppida ibéricos del entorno, son pocos los datos que tenemos. Ya hemos comentado la reducción del perímetro de Saitabi, o mejor su reorientación hacia el valle del

7 Véase sobre este tema F. Sala y J. Moratalla (eds.) (2014): Las Guerras Civiles romanas en Hispania: una revisión histórica desde la Contestania, y en especial el trabajo de A. Morillo Cerdán en el mismo libro. 

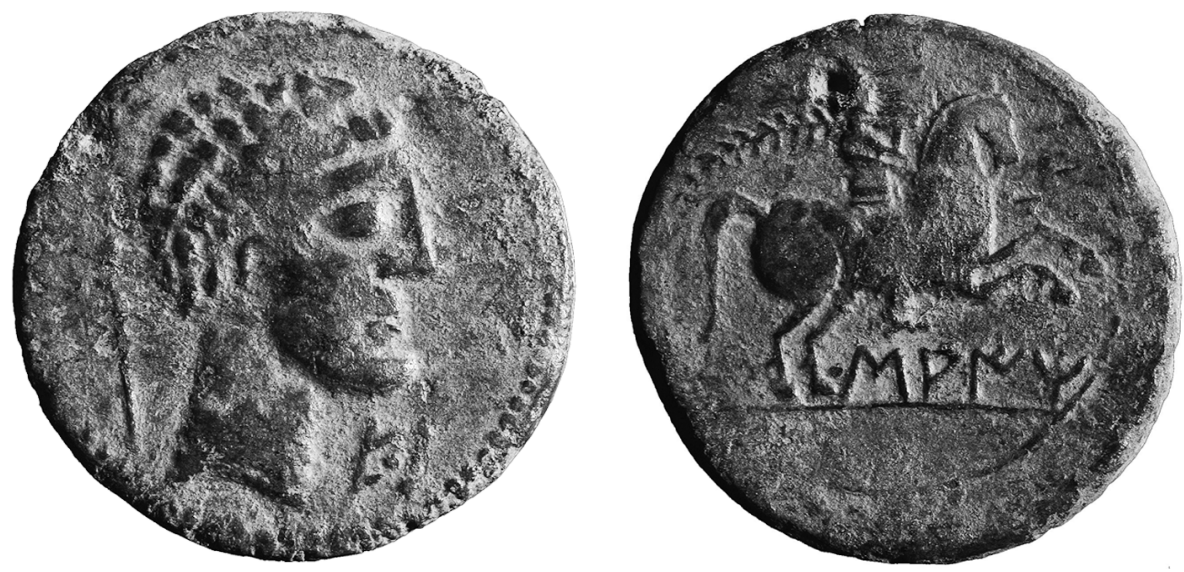

Figura 18 a y b. Bronce de Saitabi. Grupo IV de Ripollés (2007).
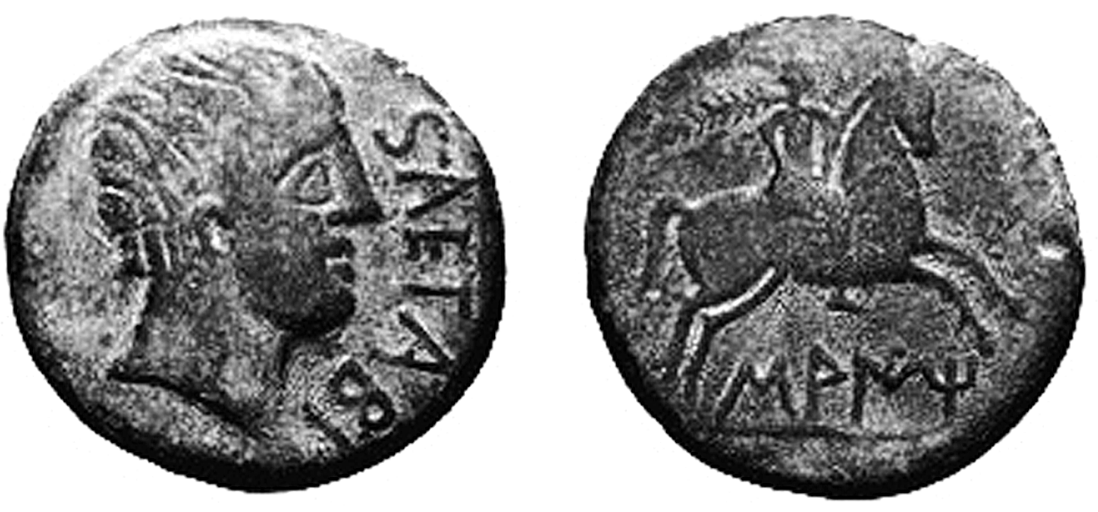

Figura 19. Bronce de Saitabi. Grupo VI de Ripollés (2007). 
Cànyoles, que va a jugar un importante papel en las comunicaciones con la Meseta, a través del acondicionamiento del paso natural con la Vía Augusta. Recientes excavaciones llevadas a cabo por J.J. Castellano en Cerro Lucena (Enguera), oppidum principal de la comarca vecina de La Canal de Navarrés y apenas a $15 \mathrm{~km}$ de Saitabi, demuestran que es abandonado justo hacia el primer cuarto del s. I a.C.; en el de Sant Antoni (Castelló de Rugat) en el límite sudeste de la Vall d'Albaida a 17km de Saitabi, se recogen en superficie materiales romanos republicanos como los comentados, sin presencia de otros más modernos, lo que hace presagiar también su abandono. Lo mismo podemos decir del oppidum de Castellaret (Moixent) correspondiente a la necrópolis de Corral de Saus, cuyas tumbas más recientes se datan en el cambio de siglo II a I a.C. En La Carència (Kili) como en Saitabi, ya hemos visto que se sigue acuñando moneda en momentos postsertorianos; las prospecciones de Gil Mascarell y las recientes excavaciones de R. Albiach (2013) nos hablan de la presencia de materiales tardorrepublicanos, pero también de una continuidad de hábitat en época imperial, como en Xàtiva, ciudad que se convertirá con Augusto en municipium romano como Saetabis Augustanorum.

\section{BIBLIOGRAFÍA}

ALBIACH DESCALS, R. (coord.) (2013): L'Oppidum de La Carència de Torís i el seu territori, València, Serie de Trabajos Varios, 116, Diputació de València.

BARROSO BERMEJO, R. (2002): "Cuestiones sobre las cerámicas grafitadas del Bronce Final y la I Edad del Hierro en la península Ibérica", Trabajos de Prehistoria, 59,1, 127-142.

CLAUSELL CANTAVELLA, G. (2004): "El Torrelló del Boverot: del Bronce medio al comienzo del Hierro", en Hernández, M. y Hernández, L. (eds.), La Edad del Bronce en tierras valencianas y zonas limítrofes, Alicante, 167-176.

GARCÍA, D., TRÉZIGNY. H. (2010): "Maisons à ábsides dans le monde grec en Gaule Méditerranéenne", en Trézigny, H. Grecs et Indigenes de la Catalogne à la mer Noire. Actes des rencontres du programme européen Ramses, 2 (2006-2008), 371-378.

GIL MASCARELL, M. (1981): Bronce tardio y Bronce Final en el País Valenciano, Monografías del Laboratorio de Arqueología de Valencia, 1, 9-39.

GONZÁLEZ PRATS, A. (1985): "La Peña Negra II y III. Campañas de 1978 y 1979”, Noticiario Arqueológico Hispánico, 21, 9-155.

GONZÁLEZ PRATS, A. (coord. y ed.) (2011): La Fonteta: excavaciones de 1996 a 2002 en la colonia fenicia de la actual desembocadura del río Segura, Guardamar del Segura, Alicante, vol. 1, Alicante.

GONZÁLEZ PRATS, A. (coord. y ed.) (2014): La Fonteta-2. Estudio de los materiales arqueológicos hallados en la colonia fenicia de la actual desembocadura del río Segura, Guardamar del Segura, Alicante, vols. 1 y 2, Alicante. 
GUÉRIN, P. (2003): El Castellet de Bernabé y el horizonte ibérico pleno edetano, Serie de Trabajos Varios, 101, Museu de Prehistòria de València, València.

HERNÁNDEZ PÉREZ, M. (2005): "La Contestania ibérica desde la Prehistoria", en: Abad, L., Sala, F., Grau, I. (eds.), La Contestania Ibérica, treinta años después, Alicante, 17-36.

IBORRA ERES, P. (2004): La ganadería y la caza desde el Bronce Final al Ibérico Final en el territorio valenciano, Valencia, Serie de Trabajos Varios, 103, Diputació de València.

MARTÍ OLIVER, B., DE PEDRO, M.J. (1997): "Sobre el final de la Cultura del Bronce Valenciano: problemas y progresos", Saguntum, 30, 59-91.

MATA PARREÑO, C. (2019): De Kelin a Los Villares (Caudete de las Fuentes, Valencia). Nacimiento y decadencia de una ciudad ibera. Serie de Trabajos Varios, 122 (2 vols.), Museu de Prehistòria de València, València.

MORILLO CERDÁN, A. (2014): “Campamentos y fortificaciones tardorrepublicanos en Hispania”, en F. Sala y J. Moratalla (eds.), Las Guerras Civiles romanas en Hispania: una revisión histórica desde la Contestania, 35-49, Alicante.

NICKELS, A. (1989): "La Monedière à Bessan (Hérault). Le bilan de recherches", Documents d'Archéologie Meridionales, 12, 51-119.

ORTIZ TEMPRADO, R. (2014): “La cerámica a mano" en: González Prats, A. (ed.), La Fonteta-2, 2, 13-238, Alicante.

PÉREZ BALLESTER, J. (2014a): "Entre el Bronce Final y el Hierro Antiguo. Las cerámicas a mano de La Solana del Castell (Xàtiva, València)", Lucentum, XXXIII, 23-40.

PÉREZ BALLESTER, J. (2014b): “El Xúquer, Saitabi y Sertorio” en: Sala, F. y Moratalla, J. (eds.), Las Guerras Civiles Romanas en Hispania. Una revisión histórica desde la Contestania, Universidad de Alicante, 51-64.

PÉREZ BALLESTER, J. (2017): "Las cerámicas griegas de La Solana del Castell (Xàtiva) en el contexto del Xúquer y la Contestania Norte”, en: Arasa, F. y Mata, C. (eds.), Homenaje a la profesora Carmen Aranegui Gascó, Saguntum Extra 19, 161-171.

PÉREZ BALLESTER, J., BORREDÁ, R. (1998): "El poblamiento ibérico del Valle del Cányoles. Avance sobre un proyecto de evolución del paisaje en la comarca de La Costera (Valencia)", Saguntum, 31, 133-152.

PÉREZ BALLESTER, J., BORREDÁ, R. (2008): “El territorio y el poblamiento ibérico de Saitabi" en: Pérez Ballester, J. (coord.), Arqueología, Historia de Xàtiva, vol. 1, València, Universitat de València, 269-286.

PÉREZ BALLESTER, J., RODRÍGUEZ TRAVER, J.A. (2008): “Las cerámicas ibéricas de Saitabi. Una aproximación” en: Pérez Ballester, J. (Coord.), Arqueología, Historia de Xàtiva, vol. 1, València, Universitat de València, 319-332.

PÉREZ BALLESTER, J., VELASCO BERZOSA, A., BORREDÁ MEJÍAS, R., RODRÍGUEZ TRAVER, J.A. (2008): “Excavaciones arqueológicas en el solar de la antigua Saitabi (La Solana del Castell, Xàtiva). Campaña de 2008”, Saguntum, 40, 237-242. 
PÉREZ BALLESTER, J., VELASCO BERZOSA, A., BORREDÁ MEJÍAS, R., RODRÍGUEZ TRAVER, J.A. (2010): "Excavaciones en La Solana del Castell (Xàtiva). Campaña de 2009", Saguntum, 42, 111-114.

PÉREZ BALLESTER, J., VELASCO BERZOSA, A., BORREDÁ MEJÍAS, R., RODRÍGUEZ TRAVER, J.A. (2011): "La Solana del Castell (Xàtiva). Campaña de 2010", Saguntum, 43, 199-204.

PÉREZ BALLESTER J., VELASCO BERZOSA, A., BORREDÁ MEJÍAS, R., RODRÍGUEZ TRAVER, J.A. (2013): "Campañas de excavaciones de 2011 y 2012 en La Solana del Castell (Xàtiva)", Saguntum, 45, 243-245.

RIPOLLÉS ALEGRE, P.P. (2007): Las acuñaciones de la ciudad ibérica de Saitabi, València, Universitat de València.

RODRÍGUEZ TRAVER, J.A. (2008): "Los antecedentes" en: Pérez Ballester, J. (coord.), Arqueología, Historia de Xàtiva, vol. 1, València, Universitat de València, 257-267.

SALA, F., MORATALLA, J. (eds.) (2014): Las Guerras Civiles romanas en Hispania: una revisión histórica desde la Contestania, Universitatd'Alacant, Alicante.

VIVES FERRÁNDIZ, J. (2006): "Negociando encuentros. Situaciones coloniales e intercambios en la costa oriental de la península Ibérica (ss. VIII-VI a.C.)", Barcelona, Cuadernos de Arqueología mediterránea, 12, Publ. Universitat Pompeu Fabra. 
